\title{
Mit patentierter \\ Faserverstärkung in die Zukunft
}

GC stellt mit Restsaurationskonzept everX Posterior ein leistungsfähiges Material zur Verfügung, das neue Möglichkeiten in der

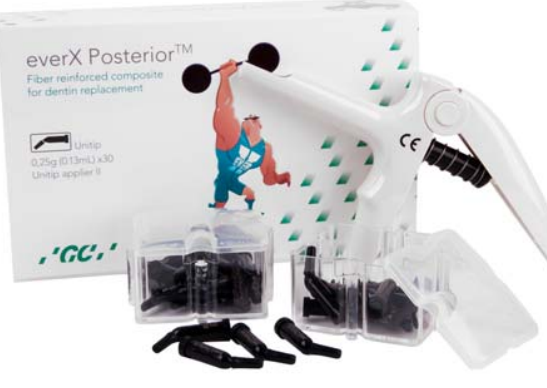

Füllungstherapie eröffnet und sich besonders als Verstärkung für direkte Komposit-Versorgungen bei großen Kavitäten im posterioren Bereich eignet. Dabei findet das glasfaserverstärkte Komposit-Material - in Kombination mit einem konventionellen Komposit als Zahnschmelzersatz - als Dentinersatz Verwendung. Weil seine kurzen Glasfasern entstehende Frakturen in der fertigen Füllung effektiv vorbeugen, ist das Material die Antwort des Unternehmens auf die zunehmende Nachfrage nach einer preiswerten Restaurationsalternative für große Kavitäten. Für ein optimales ästhetisches Ergebnis ist ein Überzug mit einem lichthärtenden Universal-Komposit wie zum Beispiel aus der G-ænial-Produktfamilie von GC nötig. Mehr zu everX Posterior unter www.gceurope.com

Nach einer Pressemitteilung der GC Germany GmbH, Bad Homburg

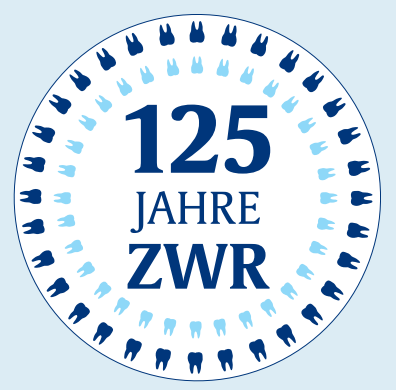

